\title{
Impact of Automobile Exhaust on Levels of Lead in a Commercial Food From Bus Terminals
}

\author{
AWOFOLU, O R \\ Department of Chemistry, Faculty of Science, Lagos State University, Badagry Expressway Ojo, P.M.B 1087, Apapa Lagos, Nigeria
}

\begin{abstract}
The impact of automobile exhaust on the levels of lead in commercially produced and sold white bread at bus terminals in Lagos, Nigeria were assessed. Total lead concentrations by Atomic Absorption Spectrometry were carried out. The mean concentration of lead in foods across the sites (T1-T10) ranged from 0.01 $-0.025 \mu \mathrm{gg}^{-1} ; 0.01-0.03 \mu \mathrm{gg}^{-1} ; 0.015-0.035 \mu \mathrm{gg}^{-1}$ and $0.005-0.025 \mu \mathrm{gg}^{-1}$ for the first, second, third and fourth periods of sampling respectively. The overall mean concentration of the metal varied between $0.015-0.026 \mu \mathrm{gg}^{-1}$ across the sampled sites. The analytical protocol was validated through the quality assurance experiment with quantitative recovery of $92.5 \%$ and C.V of $5 \%$, which was considered applicable for routine analyses of food samples. The metal was detected in over $80 \%$ of the 160 samples that were collected and analyzed. @JASEM
\end{abstract}

The ubiquity of lead and its known toxicity to man and wildlife necessitates its` continual determination in the environment. The monitoring of this metal in foods is of particular importance because it is one of the major routes by which toxic substances find their way into the human body. Primary source is mainly from natural weathering of geological materials and soils (Shea, 1996). Other sources include industrial effluents (Asamit, 1994), domestic effluents (Dean et al 1972), surface water run offs (Field and Lager, 1975) etc. However, another major contributing source of environmental lead burden is from the automobile and industrial machinery exhaust from the internal combustion engines. The use of organic lead compounds such as tetraethyl lead and tetra methyl lead as additives in petrol has been of continual concern to environmental scientists and policy makers. Studies have shown that the body lead levels of modern humans are about 500 times higher than those of pre-industrial times. It has been pointed out that Africa's contribution to global lead pollution has increased from just $5 \%$ in the 1980 s to $20 \%$ in 1996 (Nriagu, 1978). The level of lead in petrol in Nigeria was estimated as $0.7 \mathrm{~g} /$ liter and the national consumption of petrol in the country is estimated at 20 million liters per day with about 150 people per car. It was therefore predicted that at least $15,000 \mathrm{~kg}$ of lead is emitted into the environment through burning (Agbo, 1997). Hence, automobile exhaust were believed to account for more than $80 \%$ of the air pollution and lead content in Nigeria's super grade gasoline is $600-800 \mathrm{mg} / \mathrm{liter}$ (Osibanjo and Ajayi, 1989; Shy, 1990), which is much higher than permissible levels in some pollution conscious countries.

\section{MATERIALS AND METHODS}

Samples and Sampling Sites: White bread samples, which are displayed for selling, were purchased directly from food vendors at bus terminals along the Badagry Expressway Ojo, Lagos. The Expressway is a very busy international road leading to neighbouring country of Benin Republic. The food vendors normally purchase them from commercial bakeries and then taken to the terminals for selling. Samples were purchased from food vendors at bus terminals rather than roadside vendors because the former are regular, enjoying more patronage and do not experience constant displacement by the local authority. A total of 160 food samples over a period of four months were collected from bus terminals and analyzed for their lead contents.

Chemicals: All chemicals used were of analytical grades and all glassware were properly washed with liquid soap, rinsed with water, soaked in dilute acid $\left(10 \% \mathrm{HNO}_{3}\right)$ overnight and then rinsed with double distilled water before use. The metal standard solutions were prepared from 1000-ppm stock solution of the metal.

Instrumentation: Flame atomic absorption spectrometer, Pye Unicam Phillips model PU900X was employed in the determination of the metal. All the operational conditions in the instrumentation manual were followed.

Analyses of food samples: The food samples were air-dried for about 2-3 days in a clean laboratory environment and further dried in the oven at $100^{\circ} \mathrm{C}$ for about 24 hours. The dried samples were pulverized in a clean and acid rinsed $\left(10 \% \mathrm{HNO}_{3}\right)$ agate mortar. The samples were digested using the procedure described by Puchyr and Shapiro (1986). Briefly, $10 \mathrm{~g}$ of the homogenized samples was weighed into $250 \mathrm{ml}$ Erlenmeyer flask and $20 \mathrm{ml}$ of the acid mixture $\left(\mathrm{HCl}-\mathrm{HNO}_{3} ; 9+1\right)$ added. The flask was heated on a hot water bath at $90^{\circ} \mathrm{C}$ for about 30 minutes. The digested sample was allowed to cool and then filtered using Whatman Filter No 542 into $50 \mathrm{ml}$ standard flask. The Erlenmeyer flask was rinsed twice with small portions of doubly distilled water and then filtered into the $50 \mathrm{ml}$ standard flask. Blank

*Corresponding author: E-mail: orawofolu3@yahoo.com

Tel No: +234-8033239807 
determination using the same procedure was carried out and the digested samples analyzed on the AAS. Triplicate digestion of each sample was carried out and analyzed.

Quality assurance: Due to unavailability of Standard Reference Material (SRM) in our laboratory, standard addition method of the metal was used for the validation of the analytical protocol. The food sample was spiked with $1 \mathrm{mg}$ of the metal standard and then taken through the chemical analysis as described above. Three replicate analyses of the recovery tests were also carried out.

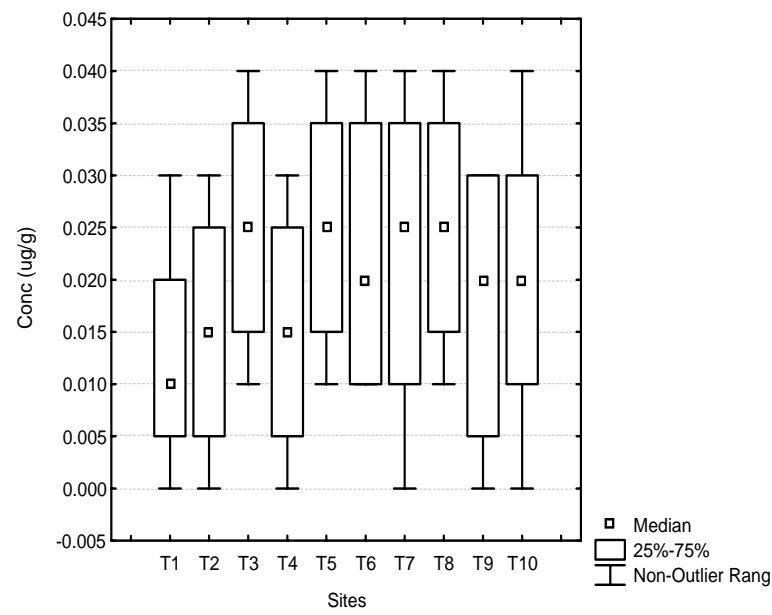

Fig 1: Mean concentration of $\mathrm{Pb}$ vs. sampling sites during first sampling period

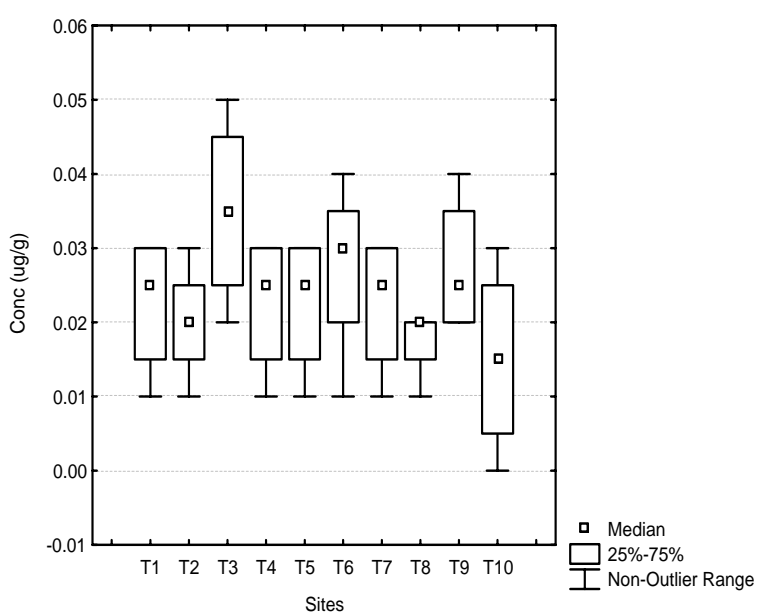

Fig 3: Mean concentration of $\mathrm{Pb}$ vs. sampling sites during the fourth

\section{RESULTS AND DISCUSSION}

The percentage recovery of $92.5 \%$ with C.V of $5 \%$ obtained for the quality assurance of the experimental protocol validates the process, which could be adjudged acceptable. Results of the determination of $\mathrm{Pb}$ in food samples are presented in Fig. 1- 4. The mean concentration of $\mathrm{Pb}$ obtained during the first period varied between $0.01-0.025 \mathrm{ggg}^{-1}$ while the second period also ranged between $0.01-0.03 \mu \mathrm{gg}^{-1}$. The third period recorded a mean concentration range of $0.015-0.035{\mu g^{-1}}^{-1}$ while the range obtained for the fourth period varied between $0.005-0.025 \mu \mathrm{gg}^{-1}$. The overall mean concentration of $\mathrm{Pb}$ ranged

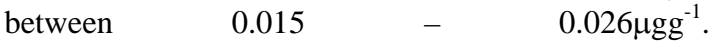

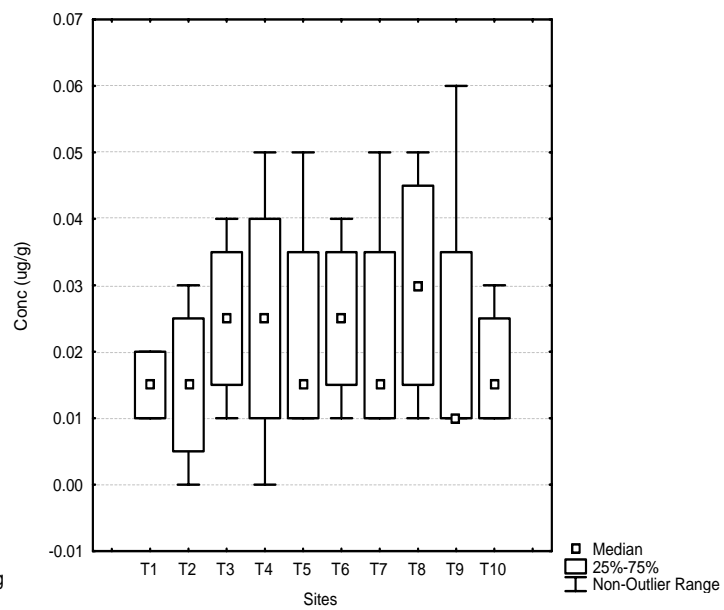

Fig 2: Mean concentration of $\mathrm{Pb}$ vs. sampling sites during the second period.

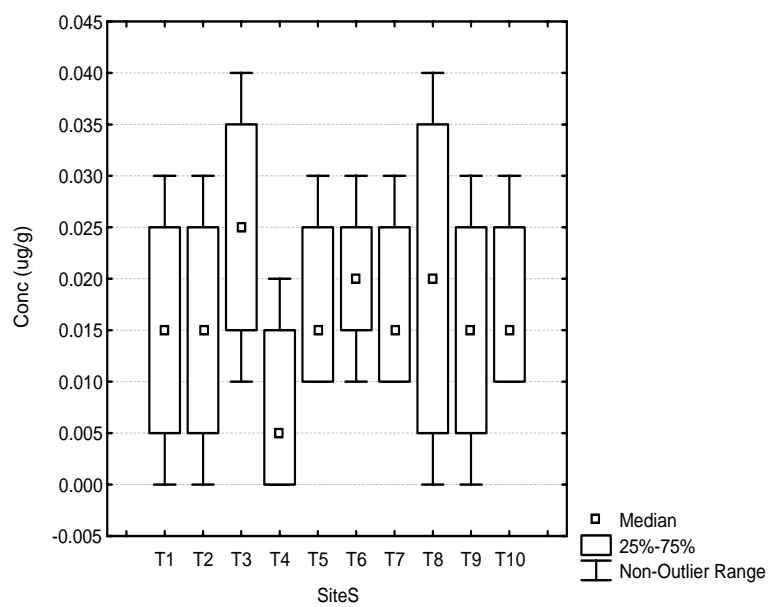

Fig 4. Mean concentration of $\mathrm{Pb}$ vs. sampling sites $\mathrm{Pb}$ vs. I period. 
The highest mean concentration of $0.025 \mu \mathrm{gg}^{-1}$ was recorded at sites T3, T5, T7 and T8 during the first period while $0.03 \mu \mathrm{gg}^{-1}$ was obtained as the highest mean $\mathrm{Pb}$ concentration at site T8 during the second period of sampling. 0.035 and $0.025 \mu g^{-1}$ were the highest mean concentration of the metal obtained both at site T3 for the third and fourth periods respectively. Consistent trends of higher levels of lead were observed at site T3 compared to other sites during the first, third and fourth periods of sampling. The same trend was observed at site T8 during the first and seconds periods. The results obtained generally revealed the presence of the metal in over $80 \%$ of the 160 food samples that were collected and analysed. White bread is a popular food that is consumed by all categories of people from the low, middle and high-income earners. Although, the high-income category would prefer to purchase their bread from departmental stores and supermarkets, majority of the lowincome earners usually patronise the vendors and hawkers. The compatibility of this food with others makes it very popular. For example, the white bread could be eaten with stew, butter, cooked beans, sausages, eggs etc. Terminal workers such as bus drivers, fare collectors, artisans and even passengers usually purchase the food from vendors at these terminals. The bread are mostly uncovered making them susceptible to atmospheric deposition of lead and are often eaten directly.

Leaded petrol is still in use in Nigeria (Osibanjo and Ajayi, 1989; Agbo, 1997) and a good percentage of the commercial buses is not road worthy with high volume of exhaust smoke released into the environment. Inhalation of the smoke containing toxic gases such as $\mathrm{NO}_{\mathrm{x}}, \mathrm{CO}_{\mathrm{x}}$ etc by people in the immediate vicinity are also very dangerous to human health. Atmospheric deposition of $\mathrm{Pb}$ compounds on exposed foods at the terminals is highly probable since leaded fuel is still marketed in the country. Atmospheric deposition of $\mathrm{Pb}$ has been reported as the major contributor of $\mathrm{Pb}$ to a lake sediment burden (Outridge et al 2002). It has also been found as the major source of $\mathrm{Pb}$ in Bombay city, India (Tripathi et al 1993).

Although, other possible contributing sources of the metal during the baking process such as the baking flour, water added etc could not be ruled out. Food vendors at terminals usually patronize varied bakeries hence the sources of the samples could not be easily identified. Atmospheric deposition of lead compounds from vehicular exhaust could be regarded as the most probable and significant source of the metal in the analysed food samples. The recommended values of $\mathrm{Pb}$ in and on foodstuffs (sausages, potatoes and wheat grains) by (WGFHA, 1986) were $0.25,0.25$ and $0.3 \mathrm{mg} \mathrm{kg}^{-1}$ respectively. The Australia New Zealand Food Standards (FSANZ, 2003) for contaminants and residues in foods recommended a value of 0.2 $\mathrm{mg} / \mathrm{kg}$ as the maximum level of lead in Cereals, Pulses and Legumes. Furthermore, the Provisional Tolerable Weekly Intake of $\mathrm{Pb}$ for man (WHO, 1972) was set at $0.05 \mathrm{mg} / \mathrm{kg}$ body weight and 3.0 $\mathrm{mg} /$ person. The mean concentrations obtained in this study were generally lower than all the recommended standards.

However, continual consumption of these foods at this level of pollution could result in accumulation in the body of consumers with serious health implications. The accumulation of $\mathrm{Pb}$ in edible aquatic plants (Kumar et al 2002) in soil and vegetation (Fatoki, 2003) and in animals (Salanki et al 2003; Wilkinson et al 2003; Metcheva et al 2003) has been reported. Although the main target of lead toxicity is the red blood cell, Pb-associated changes in the nervous system, the kidney and the reproductive system have also been reported. Studies of lead toxicity conducted on female revealed mostly miscarriages, premature delivery and infant mortality in humans and animals. A low lead concentration in the ovary was also found to cause dysfunction of folliculogenesis, with fewer primordial follicles and an increase in atretic antral follicles (Taupeau et al 2001). Pb is a non-essential toxic metal with no known beneficial effect to man even in small quantity (Tyler, 1981; Moly, 1984). Long term or chronic exposure to lead has been associated with cognitive and other deficits in humans, which may reflect lead-induced changes in synaptic development function (Morley et al 2003). The neurotoxicological effects of $\mathrm{Pb}$ in terms of cognitive performance of exposed rats have also been reported (Strupp et al 2000). Children are also fed with this food from the sampled areas. This might be contributing to some ailment such as retardation being observed in children from developing countries where leaded gasoline is still predominantly used. Schwartz reported that there was stronger evidence for an association between lead exposure and growth retardation (Schwartz et al 1986). The International Agency for Research on Cancer (IARC, 1987) has determined that there is sufficient evidence from animal studies to classify lead compounds as possibly carcinogenic to humans; group 2B. United States Environmental Protection Agency (USEPA) has also assigned lead a weight-of-evidence carcinogen classification of B2, which indicates 
that lead is a probable human carcinogen (IRIS, 1999). All the above mentioned health problems associated with lead are indications of the need to continually monitor, control and take necessary policy decisions so as to limit and ultimately prevent these avoidable health problems. The ubiquity of lead in the environment and the detection of the metal in the analysed foods is of great concern due to its` toxicity and health implication to man and wildlife. Accumulation of the metal in consumers could occur with continual ingestion of these foods at the levels obtained in this study. This highlight the importance of regular monitoring and assessment since $\mathrm{Pb}$ is known to be toxic even in small amount.

\section{REFERENCES}

Agbo, S (1997). Effects of lead poisoning in children, in Proceedings at a Workshop on Vehicular Emission and Lead Poisoning in Nigeria, Eds. Falomo A. A and Chikwendu, C. C. Organised by Friends of the Environment (FOTE) Lagos, 20-28.

Asamit, B. (1994). Environmental pollution by cadmium and zinc discharged from a Braun tube factory, Ibaraki Daigaku Nogakubu Gakujutsu Hokakn 22, 19-23.

Dean, J. G.; Bosqui, F. L; Lanouette, V H. (1972). Removing metals from wastewater. Environ. Sci. Technol. 6:518-522.

Fatoki, O. S. (2003). Lead, Cadmium and Zinc accumulation on soil and vegetation along some selected major roads of Eastern Cape. Int. J. Environ. Studies. 60:2:199-204.

Field R. A.; Lager, T. A (1975). Urban runoff pollution control-state-of-the-art. J. Environ. Eng. Div. ASCE, 101 (EE-1), 107-125.

FSANZ, (2003). Australia-New Zealand Food Standards (formerly ANZFA), Canberra and Wellington, Standards for contaminants and residues. (http://www.foodstandards.gov.au (accessed Mat 2003).

IARC, (1987). International Agency for Research on Cancer. IARC monographs on the evaluation of the carcinogenic risks of chemicals to humans: Overall evaluations of carcinogenicity. Suppl 7: An updating of the IARC monographs, volumes 1 - 42, Lyon, France: World Health Organization, Int. Agency for Research on Cancer, 230-232.
IRIS, (1999). Integrated Risk Information System. U. S Environmental Protection Agency, Office of Health and Environmental Assessment. Environmental Criteria and Assessment Office, Cincinnati, $\mathrm{OH}$.

Kumar, M.; Chikara, S.; Chand, M K.; Bhatnagar, A. K (2002). Accumulation of lead, cadmium, zinc and copper in the edible aquatic plants Trapa bispinosa Roxb and Nelumbo nucifera Gaertn. Bull. Environ. Contam. Toxicol. 69:649654.

Metcheva, R.; Teodorova, S.; Topashka-Ancheva, M. A (2003). Comparative analysis of the heavy metal loading of small mammals in different regions of Bulgaria I: monitoring points and bioaccumulation features. Ecotoxicology and Environmental Safety, 54:2:176-187.

Moly, M. B (1984). Chemistry of living organisms. John Wiley, New York, NY.

Morley, E. J.; Hirsch, H. V. B.; Hollocher, K.; Lnenicka, G. A (2003). Effects of Chronic Lead Exposure on the Neuromuscular Junction in Drosophila Larvae. Neurotoxicology, 24:1:3541.

Nriagu, J. O (1978). Lead in the atmosphere. In: The Biogeochemistry of lead in the environment. Elsevier, Amsterdam, part A, 138-164.

Osibanjo, O.; Ajayi, S. O (1989). Trace metal Analysis of Petroleum Products by Flame Atomic Absorption Spectrometry. Nig. J. Natural Sci. 4:33-40.

Outridge P. M.; Hermanson, M. H.; Lockhart, W. L (2002). Regional variation in atmospheric deposition and sources of anthropogenic lead in lake sediments across the Canadian Arctic. Geochimica et Cosmochimica Acta, 66:20:35213531.

Puchyr, R. E.; Shapiro, R (1986). Determination of trace elements in foods by $\mathrm{HCl}-\mathrm{HNO}_{3}$ leaching and Flame Atomic Absorption Spectrometry. JAOAC, 69:5:868-870.

Salanki, J.; Farkas, A.; Kamardina, T.; Rozsa, K. S (2003). Molluscs in biological monitoring of water quality. Toxicol. Letters, 140-141:403410. 
Shea, E. E (1996). Lead regulation handbook; Government Institutes, Inc., Rockville, MD, 240.

Shy C. M (1990). Lead in Petrol: The mistake of xxth century. World Health Statistic Quarterly, 43:168-176.

Schwartz, J.; Angle, C.; Pitcher, H (1986). Relationship between childhood blood lead levels and stature. Pediatrics, 77:281-288.

Strupp, B. J.; Levitsky, D. A.; Morgan, R. E (2000). Effects of chronic lead exposure on learning and reaction time in a visual discrimination task. Neurotoxicology and Teratology. 22:337-345.

Taupeau, C.; Poupon, J.; Nome, F.; Lefevre, B (2001). Lead accumulation in the mouse ovary after treatment-induced follicular atresia. Reproductive Toxicology, 15:4:385-391.

Tripathi, R. M.; Ashawa, S. C.; Khandekar, R. N (1993). Atmospheric deposition of $\mathrm{Pb}, \mathrm{Cd}, \mathrm{Cu}$ and $\mathrm{Zn}$ in Bombay, India. Atmospheric Environment Part B, Urban Atmosphere, 27:269273.
Tyler, T. G (1981). Heavy metals in soil biology and biochemistry. Soil Biochemistry, Marcel and Dekker, New York.

WGFHA, (1986). West German Federal Health Agency. Recommended Guideline Values for Cadmium, Lead and Mercury in and on Foodstuffs. Bundesgesundheitsblatt, 29:22-23.

WHO, (1972). World Health organization. Evaluation of Certain Food Additives and the Contaminants Mercury, Lead and Cadmium. $16^{\text {th }}$ Report of the Joint WHO/FAO Expert Committee on Food Additives. WHO Tech. Rep. Ser. 505, Geneva.

Wilkinson, J. M; Hill, J.; Hillman, J. P (2003). The accumulation of potentially toxic elements in edible body tissues of lambs grazing after a single application of sewage sludge. Water Research, 37:1:128-138. 